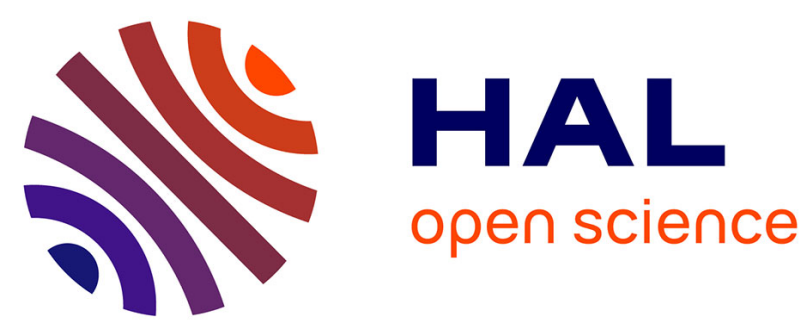

\title{
AC Transport Losses Calculation in a Bi-2223 Current Lead Using Thermal Coupling With an Analytical Formula
}

Kévin Berger, Jean Lévêque, Denis Netter, Bruno Douine, Abderrezak Rezzoug

\section{To cite this version:}

Kévin Berger, Jean Lévêque, Denis Netter, Bruno Douine, Abderrezak Rezzoug. AC Transport Losses Calculation in a Bi-2223 Current Lead Using Thermal Coupling With an Analytical Formula. IEEE Transactions on Applied Superconductivity, 2005, 15 (2), pp. 1508-1511. 10.1109/TASC.2005.849149 . hal-00348315

\section{HAL Id: hal-00348315 https://hal.science/hal-00348315}

Submitted on 18 Dec 2008

HAL is a multi-disciplinary open access archive for the deposit and dissemination of scientific research documents, whether they are published or not. The documents may come from teaching and research institutions in France or abroad, or from public or private research centers.
L'archive ouverte pluridisciplinaire $\mathbf{H A L}$, est destinée au dépôt et à la diffusion de documents scientifiques de niveau recherche, publiés ou non, émanant des établissements d'enseignement et de recherche français ou étrangers, des laboratoires publics ou privés. 


\title{
AC Transport Losses Calculation in a Bi-2223 Current Lead Using Thermal Coupling With an Analytical Formula
}

\author{
K. Berger, J. Lévêque, D. Netter, B. Douine, and A. Rezzoug
}

\begin{abstract}
When a superconductor is fed with an alternating current, the temperature rise created by the losses tends to reduce the current carrying capacity. If the amplitude of the current exceeds the value of the critical current, then the losses become particularly high and the thermal heating considerable. In this paper, a numerical and an analytical model which allow to estimate AC transport losses are presented. These models, which use the expression of $I_{\mathrm{c}}(T)$ and $n(T)$, are available for any applied current (below and above $I_{c}$ ). The results are compared and the validity of the analytical model is considered. Then, the analytical formula allows to easily obtain the thermoelectric balance point of the system, when the losses and the temperature do not vary any more. Moreover, a maximum value of the current transport, beyond which the balance point does not exist, is detected. Indeed, when this maximum value is exceeded, the system is not stable and, say, superconducting current leads may quench.
\end{abstract}

Index Terms-AC losses, Bi-2223 current lead, over current, quench, temperature dependence.

\section{INTRODUCTION}

H IGH temperature superconductors are usually characterized by a power law $E \sim J^{n}$ which does not take into consideration the material temperature. However, when the superconductor is at the dissipative state, the heat generated due to the losses is not negligible any more.

In a superconducting material, the parameters $J_{\mathrm{c}}$ and $n$-exponent depend on the temperature. Taking into account this dependence in the $E-J$ characteristic allows for a realistic simulation of the material behavior.

Our paper deals with the magneto thermal coupling which is shown by the experiment. Influence of the temperature dependence of the material is studied by comparing the AC transport losses with and without taking account the thermal coupling.

After the description of the considered system, the expressions for $J_{\mathrm{c}}(T)$ and $n(T)$ are given. Then, numerical and analytical models which allow to estimate the temperature of the superconductor and the AC losses are proposed. In the last part, the results obtained with these models are presented.

Manuscript received October 4, 2004

The authors are with the Research Group in Electrical engineering and Electronics of Nancy, University of Nancy, BP 239, F-54506 Vandoeuvre-lès-Nancy, France (e-mail: Kevin.Berger@green.uhp-nancy.fr; Jean.Leveque@green.uhp-nancy.fr; Denis.Netter@green.uhp-nancy.fr; Bruno. Douine@green.uhp-nancy.fr; Abderrezak.Rezzoug@green.uhp-nancy.fr).

Digital Object Identifier 10.1109/TASC.2005.849149

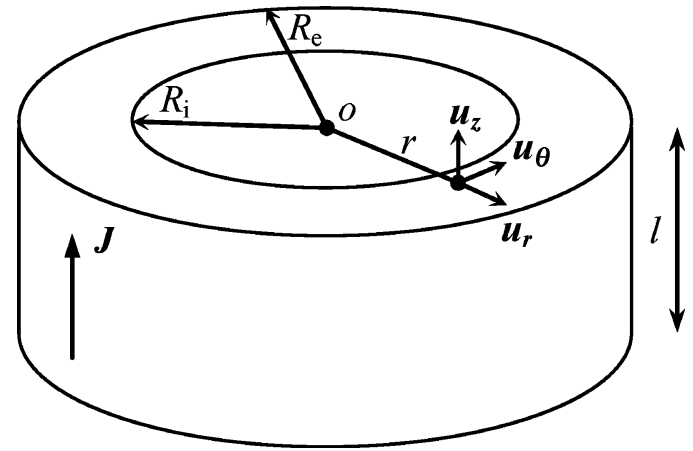

Fig. 1. Current lead description.

TABLE I

SAMPLE PARAMETERS

\begin{tabular}{lll}
\hline \multicolumn{1}{c}{ Symbol } & \multicolumn{1}{c}{ Quantity } & \multicolumn{1}{c}{ Value } \\
\hline$l$ & length & $16 \mathrm{~cm}$ \\
$R_{\mathrm{i}}$ & internal radius & $3.75 \mathrm{~mm}$ \\
$R_{\mathrm{e}}$ & external radius & $5 \mathrm{~mm}$ \\
$s$ & cross-section & $34.4 \mathrm{~mm}^{2}$ \\
$V$ & volume & $5.5 \mathrm{~cm}^{3}$ \\
$\gamma$ & density & $5 \mathrm{~g} / \mathrm{cm}^{3}$ \\
$C_{\mathrm{p}}$ & specific heat & $170 \mathrm{~J} /(\mathrm{kg} \cdot \mathrm{K})$ \\
$\lambda$ & thermal conductivity & $250 \mathrm{~W} /(\mathrm{m} \cdot \mathrm{K})$ \\
$T_{\mathrm{c}}$ & critical temperature & $108 \mathrm{~K}$ \\
$E_{\mathrm{c}}$ & critical electrical field & $1 \mu \mathrm{V} / \mathrm{cm}$ \\
$J_{\mathrm{c} 0}$ & critical current density at $77.3 \mathrm{~K}$ & $2.8 \mathrm{~A} / \mathrm{mm}^{2}$ \\
$n_{0}$ & $n$-exponent at $77.3 \mathrm{~K}$ & 21 \\
\hline
\end{tabular}

\section{STUdied SAMPLE}

The aim of this paper is to calculate the losses in a current lead fed by a sinusoidal current $i(t)=I_{\max } \sin (2 \pi f t)$. We have used a current lead made of $(\mathrm{Bi}, \mathrm{Pb})_{2} \mathrm{Sr}_{2} \mathrm{Ca}_{2} \mathrm{Cu}_{3} \mathrm{O}_{10+\delta}$ from Can Superconductors. The thermal and electrical characteristics of this current lead (Fig. 1) are given in Table I. We could not measure the thermal parameters; they are extracted from literature [1], [2].

On the basis of Anderson's excitation creep model, the exponent $n$ can be identified with $U_{0 \mathrm{a}} / k_{\mathrm{B}} T$, where $U_{0 \mathrm{a}}$ is the apparent pinning potential [3], $k_{\mathrm{B}}$ is Boltzmann's constant and $T$ is the temperature. Measurements of $J_{\mathrm{c}}$ as a function of $T$ has 
successfully been fitted to linear model in [4]-[6]. The following expressions are used:

$$
\begin{aligned}
J_{\mathrm{c}}(T) & =J_{\mathrm{c} 0} \frac{1-\frac{T}{T_{\mathrm{c}}}}{1-\frac{T_{\mathrm{bath}}}{T_{\mathrm{c}}}}, \\
n(T) & =\frac{n_{0} T_{\text {bath }}}{T} \text { with } n_{0}=\frac{U_{0 \mathrm{a}}}{k_{\mathrm{B}} T_{\text {bath }}},
\end{aligned}
$$

where $T_{\text {bath }}$ is the liquid nitrogen bath temperature, $J_{\mathrm{c} 0}$ is the critical current density at $T=T_{\text {bath }}$ and $n_{0}$ is the $n$-exponent for the case $T=T_{\text {bath }}$.

\section{MODEL DESCRIPTION}

\section{A. Numerical Model}

The electromagnetic behavior of a superconductor is governed by the Maxwell's equations. The supplement of the relation $\boldsymbol{B}=\mu_{0} \boldsymbol{H}$ gives:

$$
\nabla \times \nabla \times \boldsymbol{E}=\frac{\mu_{0} \partial \boldsymbol{J}}{\partial t} .
$$

We assume that we have $\boldsymbol{B}$ in the $\theta$ direction, $\boldsymbol{J}$ and $\boldsymbol{E}$ in the $z$ direction. Then, the problem is one-dimensional:

$$
\frac{1}{r} \frac{\partial E}{\partial r}+\frac{\partial^{2} E}{\partial r^{2}}=\mu_{0} \frac{\partial J}{\partial t} \text { with } E=E_{\mathrm{c}}\left(\frac{J}{J_{\mathrm{c}}(T)}\right)^{n(T)} .
$$

On the internal and external radius of the tube the flux density is given by the Ampere's law. The boundary conditions are connected to the flux density through $\partial E / \partial r=\partial B / \partial t$. Finally, the electromagnetic boundary conditions are:

$$
\left.\frac{\partial E}{\partial r}\right|_{r=R_{\mathrm{i}}}=0, \quad \text { and }\left.\frac{\partial E}{\partial r}\right|_{r=R_{\mathrm{e}}}=\frac{\mu_{0}}{2 \pi R_{\mathrm{e}}} \frac{d i(t)}{d t} .
$$

Let us write down the equation for the heat content of the material:

$$
\frac{\lambda}{r} \frac{\partial T}{\partial r}+\lambda \frac{\partial^{2} T}{\partial r^{2}}+E \cdot J=\gamma C_{\mathrm{p}} \frac{\partial T}{\partial t}
$$

The heat transfer is considered essentially by convection in the liquid nitrogen. Then, the thermal boundary conditions can be written as:

$$
\left.\frac{\partial T}{\partial r}\right|_{r=\left\{R_{\mathrm{i}}, R_{\mathrm{e}}\right\}}=\frac{h^{*}}{\lambda}\left(T-T_{\mathrm{bath}}\right)
$$

where $h^{*}$ is the convective heat transfer coefficient. In this liquid, the convective heat transfer coefficient is approximately $400 \mathrm{~W} /\left(\mathrm{m}^{2} \cdot \mathrm{K}\right)$ according to [7], [8].

In effect, we have to solve the following coupled problem:

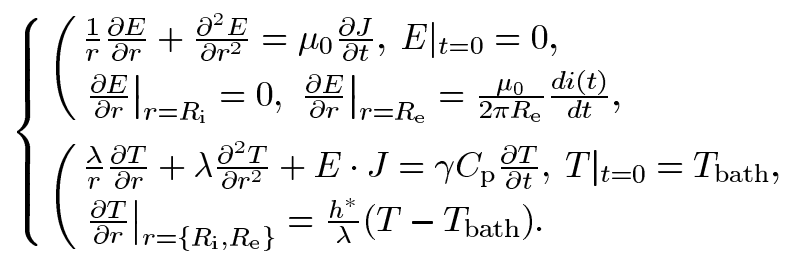

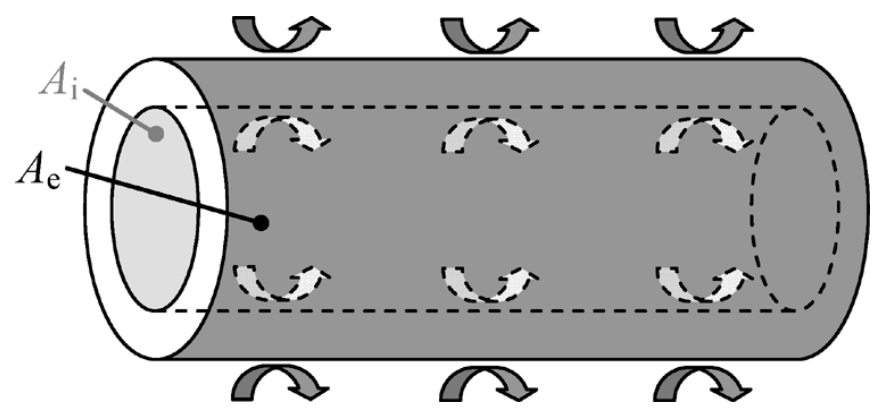

Fig. 2. Heat exchange areas considered.

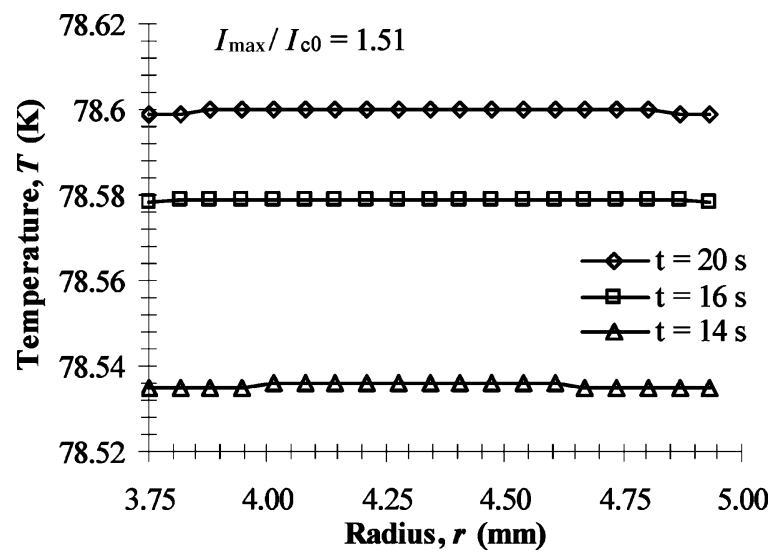

Fig. 3. Numerical results: temperature inside the superconducting current lead as a function of the radius $r$ for a reduced current amplitude $I_{\max } / I_{\mathrm{c} 0}=1.51$.

A finite difference method is used to do it. Because of the electrical time constant, a time step lower than $10^{-5} \mathrm{~s}$ is required. In order to obtain the magneto-thermal balance point, we have to wait several seconds, what generates a very long computing time.

\section{B. Analytical Model}

The value of the thermal conductivity shows an efficient heat conduction through the material. Therefore, we can assume that the temperature rise is uniform. Then, the governing equation of the superconductor's temperature is deduced:

$$
V \gamma C_{\mathrm{p}} \frac{d T}{d t}+h^{*} A\left(T-T_{\text {bath }}\right)-P=0, \quad T_{0}=T_{\text {bath }},
$$

with $A=A_{\mathrm{i}}+A_{\mathrm{e}}=2 \pi l\left(R_{\mathrm{i}}+R_{\mathrm{e}}\right) ; A$ is the total heat exchange area between the sample and the liquid nitrogen (Fig. 2). Equation (9) is discretized to enable the analytical calculation of the temperature:

$$
\begin{aligned}
T_{t+1} & =\left(T_{b a t h}+\frac{\tau}{\Delta t} T_{t}+\frac{P}{h^{*} A}\right)\left(1+\frac{\tau}{\Delta t}\right)^{-1}, \\
\Delta t & \ll \tau=\frac{V \gamma C_{\mathrm{p}}}{h^{*} A},
\end{aligned}
$$

with $\tau$ is the thermal time constant of the system, and $\Delta t$ is the time step; we used $\Delta t=1 / f$.

Recent studies [9], [10] highlighted an analytical formula making it possible to estimate the losses in self field in HTS 


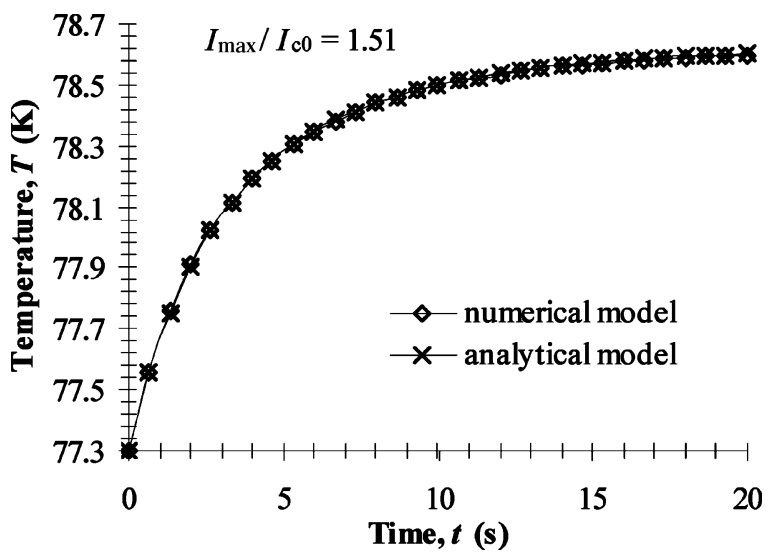

Fig. 4. Superconductor's temperature as a function of time for numerical and analytical model with $I_{\max } / I_{\mathrm{c} 0}=1.51$.
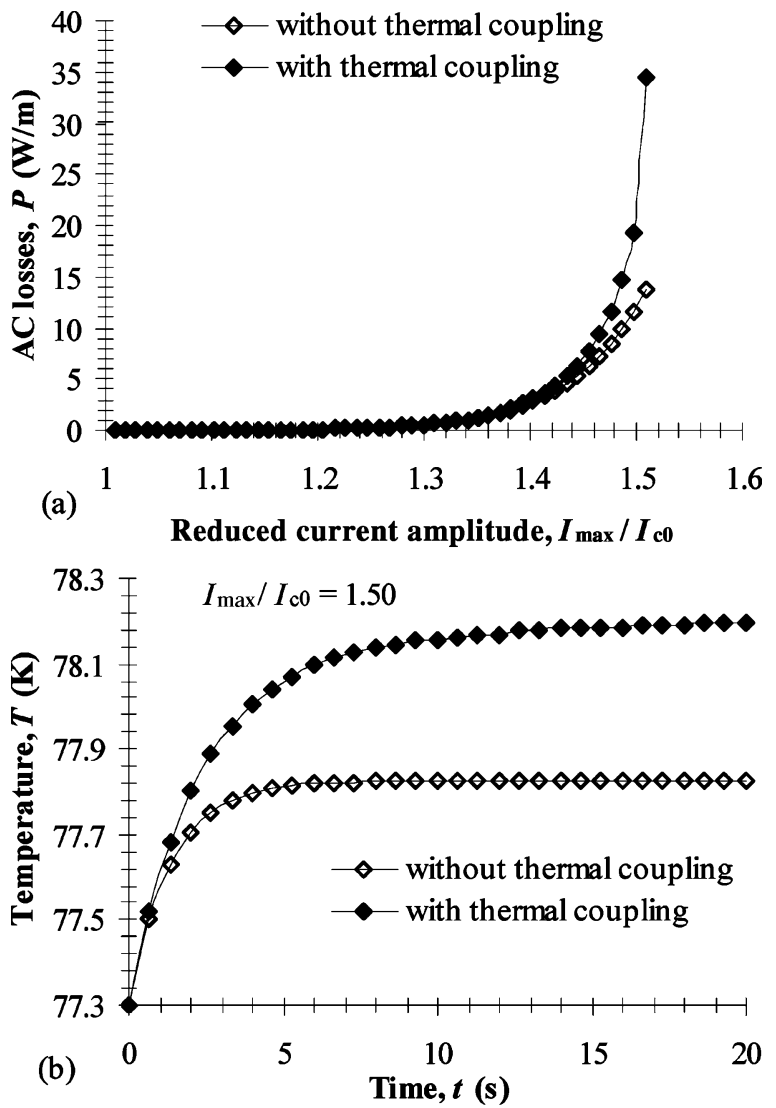

Fig. 5. Comparison of the results with and without thermal coupling: (a) AC losses as a function of reduced current amplitude. (b) Evolution of the superconductor's temperature for $I_{\max } / I_{c 0}=1.50$.

current leads. This analytical formula is deduced from a dimensional analysis. The power law $E \sim J^{n}$ used in this formula is close to reality compared to the Bean model so it brings an additional precision to the calculation of the losses. Its validity is conserved when the amplitude of the current through the superconductor is higher than the critical current $I_{\mathrm{c}}[10]$. The temperature does not occur in the analytical formula, thus
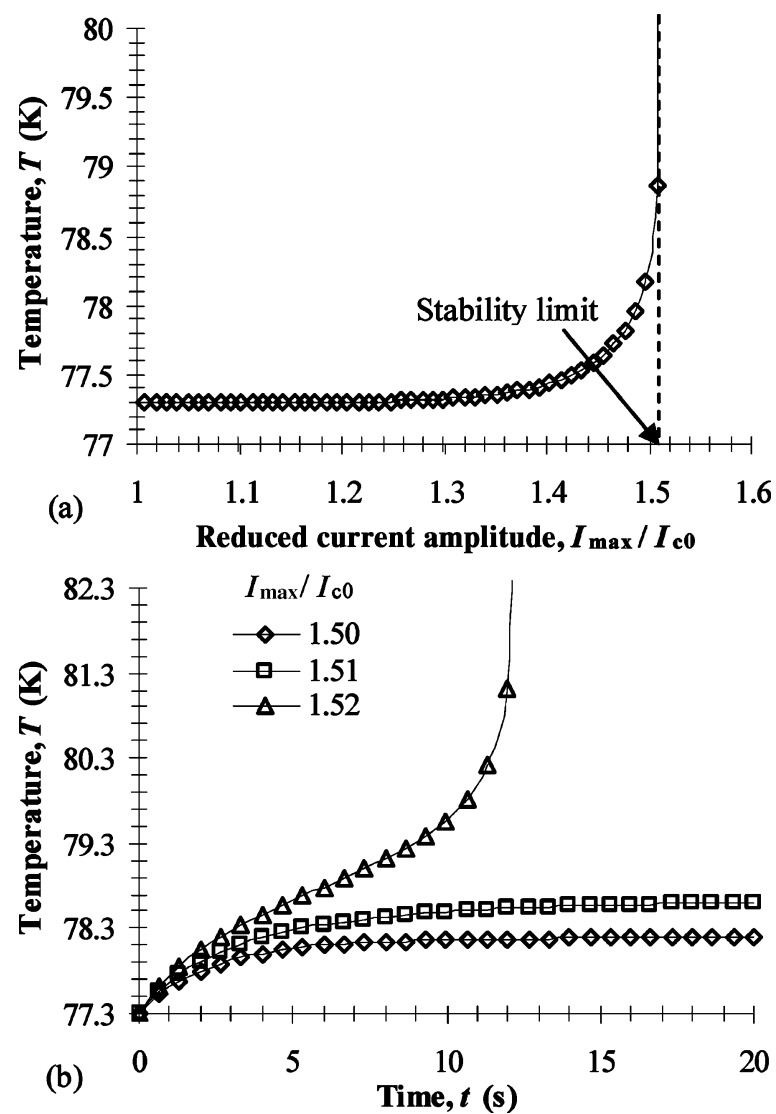

Fig. 6. With thermal coupling: (a) superconductor's temperature as a function of reduced current amplitude. (b) Evolution of the superconductor's temperature for different reduced current amplitudes.

$I_{\mathrm{c}}(T)$ and $n(T)$ are included to take into account the thermal coupling. For $I_{\max } \leq I_{\mathrm{c}}(T)$, the expression of the AC losses is:

$P=l \alpha_{\mathrm{R}}\left(\frac{1}{6 \pi}+\frac{0.3}{n(T)}\right)\left[E_{\mathrm{c}}\left(\frac{\mu_{0} f}{I_{\mathrm{c}}(T)}\right)^{n(T)} I_{\max }^{3 n(T)+1}\right]^{\frac{1}{n(T)+1}}$,

and for $I_{\max }>I_{\mathrm{c}}(T)$ :

$$
\begin{gathered}
P=l\left(\alpha_{\mathrm{R}}\left(\frac{1}{6 \pi}+\frac{0.3}{n(T)}\right)\left[E_{\mathrm{c}}\left(\mu_{0} f\right)^{n(T)} I_{\mathrm{c}}^{2 n(T)+1}(T)\right]^{\frac{1}{n(T)+1}}\right. \\
\left.+2 f \frac{E_{\mathrm{c}}}{I_{\mathrm{c}}^{n(T)}(T)} \int_{t_{1}}^{t_{2}} i^{n(T)+1}(t) d t\right)
\end{gathered}
$$

with $l$ is the current lead length, $t_{1}$ and $t_{2}$ are the instants between which $i(t)>I_{\mathrm{c}}$, and $\alpha_{\mathrm{R}}=1-R_{\mathrm{i}}^{2} / R_{\mathrm{e}}^{2}$.

For the first step, the solutions of the coupled problem are found using the initial conditions. Then, the resolution of the next steps is completed until the steady-state is reached.

\section{RESUlTS}

Fig. 3 shows the temperature inside the superconducting current lead as a function of the radius $r$ for a reduced current amplitude $I_{\max } / I_{\mathrm{c} 0}=1.51$. The temperature's distribution is nearly uniform inside the superconductor. Thus, the results by 


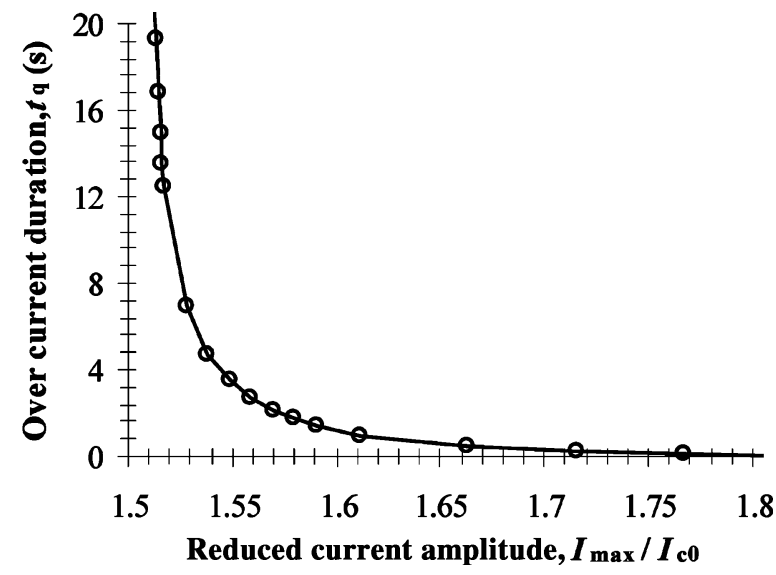

Fig. 7. Over current duration as a function of the reduced current amplitude $I_{\max } / I_{\mathrm{c} 0}$.

the numerical model show that the diffusion phenomena can be neglected as that has been made in the analytical model.

A comparison between the numerical and analytical model is presented in Fig. 4. The superconductor's temperature is plotted versus time for both the numerical and analytical models. The results are the same independently of model. However, for these 20 seconds of simulation, the numerical model costed us about 24 hours of computing time, whereas the analytical resolution is practically instantaneous. Henceforth, only results coming from the analytical model are presented.

Fig. 5 shows the influence of the thermal coupling on the AC losses. Since $I_{\max }>I_{\mathrm{c} 0}$ the losses become significant Fig. 5(a) and the influence of the thermal coupling can not be neglected. Evolution of the superconductor's temperature for $I_{\max } / I_{\mathrm{c} 0}=$ 1.50 is shown in Fig. 5(b). The deviation between the two curves is about $0.4 \mathrm{~K}$ in the steady-state. Without thermal coupling the losses are approximately of $11.5 \mathrm{~W} / \mathrm{m}$ compared to $19.2 \mathrm{~W} / \mathrm{m}$ with the coupling, that is to say, an increase of $67 \%$.

The losses dissipating in the superconductor may create a temperature rise of a few Kelvins as shown in Fig. 6(a). When $I_{\max } / I_{\mathrm{c} 0} \geq 1.52$, there is no balance point and the superconductor quenches as in Fig. 6(b). In fact, the maximum steadystate temperature of the superconductor cannot exceed $78.99 \mathrm{~K}$.

Practically, amplitude of the over current depends on the type of the load which is connected to the current lead. Fig. 7 shows the over current duration $t_{\mathrm{q}}$ as a function of the reduced current amplitude $I_{\max } / I_{\mathrm{c} 0}$. For this current lead, the over current du- ration is about 12 seconds for $I_{\max } / I_{\mathrm{c} 0}=1.52$, and the quench appears more quickly for higher current amplitudes.

\section{CONCLUSION}

Through this article, the importance of the thermal coupling in the calculation of the losses in a HTS current lead was shown. An analytical formula making it possible to calculate these losses was compared with a one-dimensional numerical model. The results of both models show a good agreement with very different computing times. Thus, for the same results, the analytical formulation is of interest.

The material required to carry out precise measurements of losses and temperature taking rather long time to set up, it was not possible to us to validate our model by the experiment. However, the breadboard is actually built and some new results should be published in this way.

\section{REFERENCES}

[1] B. des Ligneris, M. Aubin, and J. Cave, "Calorimetric study of the thermal conductivity of superconducting tapes experimental method and simulations," Physica C, vol. 354, pp. 270-274, 2001.

[2] I. Bogdanov, S. Kozub, K. Myznikov, I. Akimov, and N. Gryaznov et al., "Application of HTS Bi-2223 current leads of superconducting magnets," in Proc. 7th European Particle Accelerator Conf. (EPAC 2000), pp. 2178-2180.

[3] L. Cesnak, F. Gömöry, and P. Kováč, "Pinning potential, its relativity and dependence on temperature and magnetic field studied on the basis of the I-V characteristics of multifilamentary Nb3Sn superconductors,' Supercond. Sci. Technol., vol. 9, pp. 184-192, 1996.

[4] N. Magnusson, "Semi-empirical model of the losses in HTS tapes carrying AC currents in AC magnetic fields applied parallel to the tape face," Physica C, vol. 349, pp. 225-234, 2001.

[5] M. P. Oomen, B. ten Haken, M. Leghissa, and J. Rieger, "Optimum working temperature of power devices based on Bi-2223 superconductors," Supercond. Sci. Technol., vol. 13, pp. L19-L24, 2000.

[6] N. Schönborg and S. Hörnfeldt, "Model of the temperature dependence of the hysteresis losses in a high-temperature superconductor," Physica C, vol. 372-376, pp. 1734-1738, 2002.

[7] M. Polák, J. Kvitkovič, E. Demenčík, L. Janšák, and P. Mozola, "Temperature of Bi-2223/Ag samples in the resistive section of I-V curves,' Physica C, vol. 401, pp. 160-164, 2004.

[8] H. Reiss, "Simulation of thermal conduction and boiling heat transfer and their impact on the stability of high-temperature superconductors," High Temp.-High Press., vol. 29, no. 4, pp. 453-460, 1997.

[9] B. Douine, J. Lévêque, D. Netter, and A. Rezzoug, "Calculation of losses in a HTS current lead with the help of the dimensional analysis," Physica C, vol. 399, pp. 138-142, 2003.

[10] B. Douine, "Studies of losses in high critical temperature superconductors (Etudes des pertes dans les supraconducteurs à haute température critique)," PhD. dissertation, Henri Poincaré University, Nancy, France, 2001. 